\title{
Influence of Soaking Time and Sodium Hydroxide Concentration on the Chemical Composition of Treated Mango Seed Shell Flour for Composite Application
}

\section{1"GOVERNMENT, RM; ${ }^{2}$ OLOWOKERE, JA; ${ }^{2}$ ODINEZE, CM; ${ }^{1}$ ANIDOBU, CO; ${ }^{1}$ YERIMA, E A; ${ }^{1}$ NNAEMEKA, BI}

\author{
${ }^{l}$ Department of Chemical Sciences, Federal University Wukari Taraba State, Nigeria \\ ${ }^{2}$ Department of Chemical Engineering, Federal University of Technology, Minna, Niger State, Nigeria. \\ *Corresponding AuthorEmail: govt_4real@yahoo.com; Co-author's Email: olowojo@yahoo.com; micoatchimex@yahoo.com; \\ maryclaraandy@gmail.com; yerimaemmanuel@yahoo.com; bernardlk127@gmail.com
}

\begin{abstract}
Lignin and hemicelluloses are the major impurities to be removed in natural fibers for it to be suitable in composite application and other uses. This research is based on evaluating the influence of soaking time and sodium hydroxide concentration on the chemical composition of treated mango seed shell (MSSF) by immersing the MSSF in $\mathrm{NaOH}$ solution at concentration of $2.5-7.5 \mathrm{wt} \%$ and soaking time of 2-6 hr, in order to decrease the lignin and hemicellulose content while increasing its cellulose content. The optimum conditions obtained for concentration and soaking time of $\mathrm{NaOH}$ were $6.09 \%$ and $5.22 \mathrm{hr}$, respectively. At these conditions, cellulose content was increased to $94.8002 \%$, while the hemicelluloses and lignin content were reduced to $2.2779 \%$ and $0.508502 \%$, respectively. The process parameter of MSSF was optimized using central composite design (CCD) to predict the cellulose, hemicelluloses, and lignin content. The quadratic model of response surface model (RSM) was adopted for the prediction of cellulose, hemicelluloses, and lignin content. The maximum error between the predicted using CCD and experimental results was less $0.38 \%$. These errors in variation for both the predicted by the RSM and the actual gave good alignment with both results. Therefore, at these treatment conditions, MSSF can be utilized for composite application and other industrial purpose.
\end{abstract}

\section{DOI: https://dx.doi.org/10.4314/jasem.v23i1.3}

Copyright: Copyright $\odot 2019$ Government et al. This is an open access article distributed under the Creative Commons Attribution License (CCL), which permits unrestricted use, distribution, and reproduction in any medium, provided the original work is properly cited.

Dates: Received: 23 November 2018; Revised: 17 January 2019; Accepted 26 January 2019

Keywords: $\mathrm{NaOH}$, Chemical Modification, Mango Seed Shell Flour, Chemical Composition

Nowadays, agro-based lignocelluloses derived from plant have been major raw materials in the composite industries for the manufacturing of new products (Obasi, 2015). The new products are electronic packaging, automotive parts, building material, plastic containers, etc. The agro-based fiber mainly found as waste has totally replaced mineral fiber for the utilization of finished products. Following previous investigations, it is clear that agricultural waste abound in huge deposits in the environment (Obasi, 2015; Dungani et al, 2016). When properly harnessed, agro-wastes can reduce the threat cause by fuel and petrochemicals from plastics deposit (Obasi, 2015; Shuhaidu and Soh, 2016). The conversion of agro-waste into wealth creation is paramount for new industrial revolution. It is estimated globally that about 140 billion metric tons of agro-wastes are produced annually as a result of agro-activities which can serves as filler for polymer industry (Shuhaidu and Soh, 2016). Agro-waste as a by-product after elimination of edible part has some of these advantages: low cost, renewable, and very light.
Cellulosic materials are the largest component of plant sourced from agro-wastes with two other main parts of the lignocelluloses called hemicelluloses and lignin (Thygesen et al., 2007; Netral et al., 2012; Dungani et al., 2016; Shuhaidu and Soh, 2016). The cellulosic fiber provides better strength when used for composite utilization (Bogoeva-Gaceva et al., 2007; Netral et al., 2012). Several studies have shown that agro-based plants with high amount of cellulose content are good for the production of natural filler polymer composite (Bogoeva-Gaceva et al., 2007; Netral et al., 2012; Dungani et al., 2015; Government et al., 2017; Government et al., 2018). While the other unwanted part of natural fiber known as hemicelluloses and lignin are meant to be reduced to avoid the issues of incompatibility when employed for composite and industrial utilizations (Wu et al., 2000; Rowell, 2005; Nachtigall et al., 2007). The problem of incompatibility can lead to more water absorption when the agro-based plant has been process as industrial products after exposure for long period (Haristov and Vasileva, 2003; Nunes et al., 
2002; Government et al., 2017; Government et al., 2018). One of the processes of boosting the properties of the agro-wastes derive from plant source for composite production is through chemical modification (Nachtigall et al., 2007). The chemical treatment helps to knock down the gelly-like material found in the agro-waste and releases it in the chemical modifier solution which can be rinsed out with distilled water. Some of the chemical treatment used in purifying the lignin and other unwanted parts from agro-based plant are alkaline and acid treatment (Shuhaidu and Soh, 2016).

From previous work, it can be ascertained that treatment of agro-wastes using alkaline medium yields better results than other treatment methods (Shuhaidu and Soh, 2016; Oushabi et al., 2017; Obasi et al., 2015; Kim and Han, 2012; Iroba et al., 2013). In addition, alkaline treatment of fiber produces smaller soaking time and temperature of reactant than any other treatment process (Kim and Han, 2012; McIntosh and Vancov, 2011; Chen et al., 2007). The basic form of alkaline modifying agents used for delignification and reduction of hemicelluloses are $\mathrm{NaOH}, \mathrm{Ca}(\mathrm{OH})_{2}$ and $\mathrm{KOH}$ (Binod et al., 2010). Treatment process using alkaline solution as modifiers influence the natural fiber agro-based by dissolving the hemicelluloses in the solution, minimization of crystalinity, improving volume of pores and the surface area of the fiber (Behera et al., 2014; Camesasca et al., 2015; Shuhaidu and Soh, 2016). In the same vein, alkalization treatment of agro-based plant entails delignification of lignin and allows the dissolution of hemicelluloses branch of the fiber (Binod et al., 2010). $\mathrm{NaOH}$ as a modifier has frequently been used in the removal of unwanted components of lignocelluloses based material and has shown to be one of the best method for reduction of unwanted part of plant fiber composition (Cotanaa et al., 2015; Zheng et al., 2009). The chemical composition of plant fiber generated from agro-based source through chemical modification with $\mathrm{NaOH}$ is a function of certain variables. The variables are soaking duration, concentration of the alkali treatment, temperature of the reaction and the ratio of fiber in the alkali solution (Kim and Han, 2012; Shaihaidu and Soh, 2016; Iroba et al., 2013). However, research in this area has shown that $\mathrm{NaOH}$ treatment of agro-based has improved cellulose content and decrease hemicelluloses and lignin content. These include Shea butter bark flour (Akpake, 2017), wheat straw (Sun et al., 1995), rice straw (Kim and Han, 2012; Shaihaidu and Soh, 2016) and barley straw (Iroba et al., 2013). The present research involved the use of novel mango seed shell flour (MSSF) which is to be treated with $\mathrm{NaOH}$ with the sole aim of increasing its cellulose component through the reduction of the hemicelluloses and lignin constituent of the MSSF. The objective of this work is to study the effect of varying $\mathrm{NaOH}$ concentration and soaking time on the chemical composition of Mango Seed Shell Flour (MSSF) in order to determine their optimum conditions in composite application.

\section{MATERIALS AND METHODS}

Mango Seed Shell Flour (MSSF) Extraction: Mango seed shell flour was sourced from Wapam-Aku in Wukari Local Government Area of Taraba State.

Purchasing of $\mathrm{NaOH}$ : The $\mathrm{NaOH}$ pellets $98 \%$ extra pure w.w 40.0, was prepared by LOBA Chemie Laboratory reagents and fine chemicals Pvt. Limited, Mumbai, India. The $\mathrm{NaOH}$ was obtained in Ogbete Main Market, Ogbui, Enugu State of Nigeria.

Preparation of MSSF: The MSSF was washed with water and sun-dried for 8 hours daily for a period of 1 week. The MSSF was ground and sieved into $850 \mu \mathrm{m}$ mesh size. 10 gram of MSSF was immersed in $\mathrm{NaOH}$ solution at concentration of 2.5, 5.0, 7.5 by weight and soaking time 2, 4 and $6 \mathrm{hr}$. After treatment, the MSSF was rinsed five times with deionized water to removed hemicelluloses and lignin. The treated MSSF was sun-dried for 8 hours before the chemical characterization test was carried out using gravimetric method.

Determination of Chemical Composition of MSSF: The chemical composition of MSSF was carried out in Divine Chemical Laboratory, Nsukka Enugu State. The MSSF after passing the stages of alkali treatment was subjected to chemical composition test to determine the chemical composition by ChessonDatta gravimetric method (Mahyati et al., 2013). $1 \mathrm{~g}$ of pretreated dried MSSF (V) and $150 \mathrm{ml}$ deionized water were heated together in a beaker at a $100^{\circ} \mathrm{C}$ for 1 hour. After heating, the residue was separated out from mixture of MSSF and the deionized water by filtration process. The residue was rinsed with $300 \mathrm{ml}$ warm deionizer water. This residue was oven-heated to a steady weight $(\mathrm{W})$. The mixture of the residue and $150 \mathrm{ml}$ of $1 \mathrm{M} \mathrm{H}_{2} \mathrm{SO}_{4}$ was heated in the oil bath for $1 \mathrm{~h}$ at $100^{\circ} \mathrm{C}$. The mixture was later passed through filtration and rinsed with $300 \mathrm{ml}$ of deionized water and dried to obtain another residue $(\mathrm{X})$. The residue was immersed in $10 \mathrm{ml}$ of $72 \% \mathrm{H}_{2} \mathrm{SO}_{4}$ at ambient temperature for $4 \mathrm{~h}$ and further addition of $150 \mathrm{ml}$ of $\mathrm{I} \mathrm{M} \mathrm{H}_{2} \mathrm{SO}_{4}$ into the mixture. The mixture was refluxed in the oil bath for $1 \mathrm{~h}$. The solid generated after refluxing was rinsed with $400 \mathrm{ml}$ of deionized water, oven-heated at $105^{\circ} \mathrm{C}$ and weighed 
till a steady weight is attained (Y). The solid was further heated again till attainment of ash and finally weighed $(Z)$. The cellulose, hemicellulose and lignin content were estimated using following equations (Eq. (1), Eq. (2) and Eq. (3)):

$\%$ cellulose $=\frac{(Y-X)}{V} \times 100$

$\%$ hemicellulose $=\frac{(X-W)}{V} \times 100$

$\%$ lignin $=\frac{(Z-Y)}{V} \times 100$

Design of Experiment and Optimization: The design of experiment involved a two factors central composite model to determine optimum treatment variables to maximize the cellulose content and minimized the hemicelluloses and lignin content for composite application. The selected variables are the $\mathrm{NaOH}$ concentration (A) and soaking time of treatment $(\mathrm{B})$. The ranges of these variables were 2.5-
$7.5 \mathrm{wt} \%$ and 2-6 hr for concentration and soaking time, respectively. Using design expert software 7.0, a total of 13 runs was generated and experimented upon, using CCD option of face centered design. The chemical composition of MSSF with respect to the chemical modification for cellulose (C), hemicelluloses $(\mathrm{H})$ and lignin $(\mathrm{L})$ were chosen as response in RSM. The ANOVA analysis with help of quadratic model based on the two factor experiment at $95 \%$ confidence level was also done. Table 1 shows the range and level of parameters used in the treatment on MSSF in the central composite design. The symbol $-\alpha$ represented the smallest parameter in the CCD, -1 is the smaller term of the variable to be placed in the CCD, while 0 is the middle term of the parameters, +1 is the high term of the variable and $+\alpha$ is the highest term of the variable in the CCD (Montgomery, 2011).

Table 1: Range and Level of Parameters used in the Treatment on MSSF in the CCD

\begin{tabular}{lllllll}
\hline Variables & Unit & \multicolumn{7}{c}{ Range and level } \\
\hline & & $-\alpha$ & -1 & 0 & +1 & $+\alpha$ \\
NaOH concentration (A) & $\%$ & 2.5 & 2.5 & 5 & 7.5 & 7.5 \\
Soaking Time (B) & $\mathrm{hr}$ & 2 & 2 & 4 & 6 & 6 \\
\hline
\end{tabular}

\section{RESULTS AND DISCUSSION}

Regression model generation for prediction of composition of treated MSSF: Table 2 present design matrix of chemical composition of treated MSSF. The combination of parameters of treated MSSF: $\mathrm{NaOH}$ concentration (A) and soaking time (B) to yield the cellulose content $(\mathrm{C})$, and hemicelluloses $(\mathrm{H})$ and lignin $(\mathrm{L})$ content removal are known to be the responses. From these connecting factors and composition of treated MSSF, the regression models were produced to predict the chemical composition of pretreated MSSF for cellulose (C), hemicelluloses (H) and lignin (L) removal by applying quadratic function of RSM.

Table 2: Design Matrix of Chemical Composition of Treated MSSF

\begin{tabular}{|c|c|c|c|c|c|}
\hline \multicolumn{3}{|c|}{ Factors } & \multicolumn{3}{|c|}{ Response } \\
\hline $\begin{array}{l}\mathrm{Ru} \\
\mathrm{n}\end{array}$ & $\begin{array}{l}\text { A:NaOH } \\
\text { Concentation (\%) }\end{array}$ & $\begin{array}{l}\text { B:Soaking } \\
\text { Time (hr) }\end{array}$ & $\begin{array}{l}\text { C:Cellulose } \\
(\%)\end{array}$ & $\begin{array}{l}\text { H:Hemicellulose } \\
(\%)\end{array}$ & $\begin{array}{l}\text { L:Lignin } \\
(\%)\end{array}$ \\
\hline 1 & $2.5(-1)$ & $2(-1)$ & 77.38 & 18.17 & 4.45 \\
\hline 2 & $2.5(-1)$ & $4 \quad(0)$ & 86.42 & 10.63 & 2.95 \\
\hline 3 & $5 \quad(0)$ & $6 \quad(1)$ & 94.06 & 4.84 & 1.1 \\
\hline 4 & 7.5 (1) & $6 \quad(1)$ & 83.99 & 5.38 & 2.24 \\
\hline 5 & $7.5(1)$ & $2(-1)$ & 89.28 & 8.16 & 2.56 \\
\hline 6 & $5 \quad(0)$ & $4 \quad(0)$ & 97.21 & 2.71 & 0.08 \\
\hline 7 & (0) & $4 \quad(0)$ & 97.21 & 2.71 & 0.08 \\
\hline 8 & (0) & $2(-1)$ & 91.15 & 6.76 & 2.09 \\
\hline 9 & (0) & $4 \quad(0)$ & 97.21 & 2.71 & 0.08 \\
\hline 10 & $7.5(1)$ & $4 \quad(0)$ & 92.75 & 4.28 & 1.97 \\
\hline 11 & $5 \quad(0)$ & $4 \quad(0)$ & 97.21 & 2.71 & 0.08 \\
\hline 12 & $2.5(-1)$ & $6 \quad(1)$ & 86.87 & 10.05 & 3.08 \\
\hline 13 & $5 \quad(0)$ & $4 \quad(0)$ & 97.21 & 2.71 & 0.08 \\
\hline
\end{tabular}

These regression models were described in Eq.(4), Eq.(5) and Eq. (6).

Cellulose $(C)=23.78885+16.64278 A+14.07681 B-0.739 A B-1.26634 A^{2}-1.22366 B^{2}$

hemicellulose $(H)=50.28230-9.9809 A-8.48195 B+0.267 A B+0.75109 A^{2}+0.75983 B^{2}$

$\operatorname{Lignin}(\mathrm{L})=15.51621-3.57595 A-2.65411 B+0.31186 A^{2}+0.27103 B^{2}$ 
Analysis of Variance (ANOVA) for Predicted Quadratic Model of Treated MSSF Composition: The ANOVA results of the chemical composition of the treated MSSF is represented in Table 3. It is shown that the models for the three responses $(\mathrm{C}, \mathrm{H}$ and $\mathrm{L})$ have probability values of less than 0.05 . This means that the models for the prediction of cellulose content (C), hemicellulose $(\mathrm{H})$ and lignin content removal were highly significant. In the same vein, the coefficient of determination $\left(\mathrm{R}^{2}\right)$ for $\mathrm{C}, \mathrm{H}$ and $\mathrm{L}$ was close to one. Also, the adjusted $\mathrm{R}^{2}$ and predicted $\mathrm{R}^{2}$ values were in consonant to each other for $\mathrm{C}, \mathrm{H}$ and L. This confirms the reliability and precision of experimental results using central design model (Kuchi, 2000; Government et al., 2018; Mayers et al., 2004; Mayers et al., 2009). This related pattrern of results were also presented by other scolars (Soury et al., 2009; Hadi, 2011; Patpeni et al., 2015; Government et al., 2018).

Table 3: ANOVA of the Composition of Treated MSSF; C, $\mathrm{H}$ and L

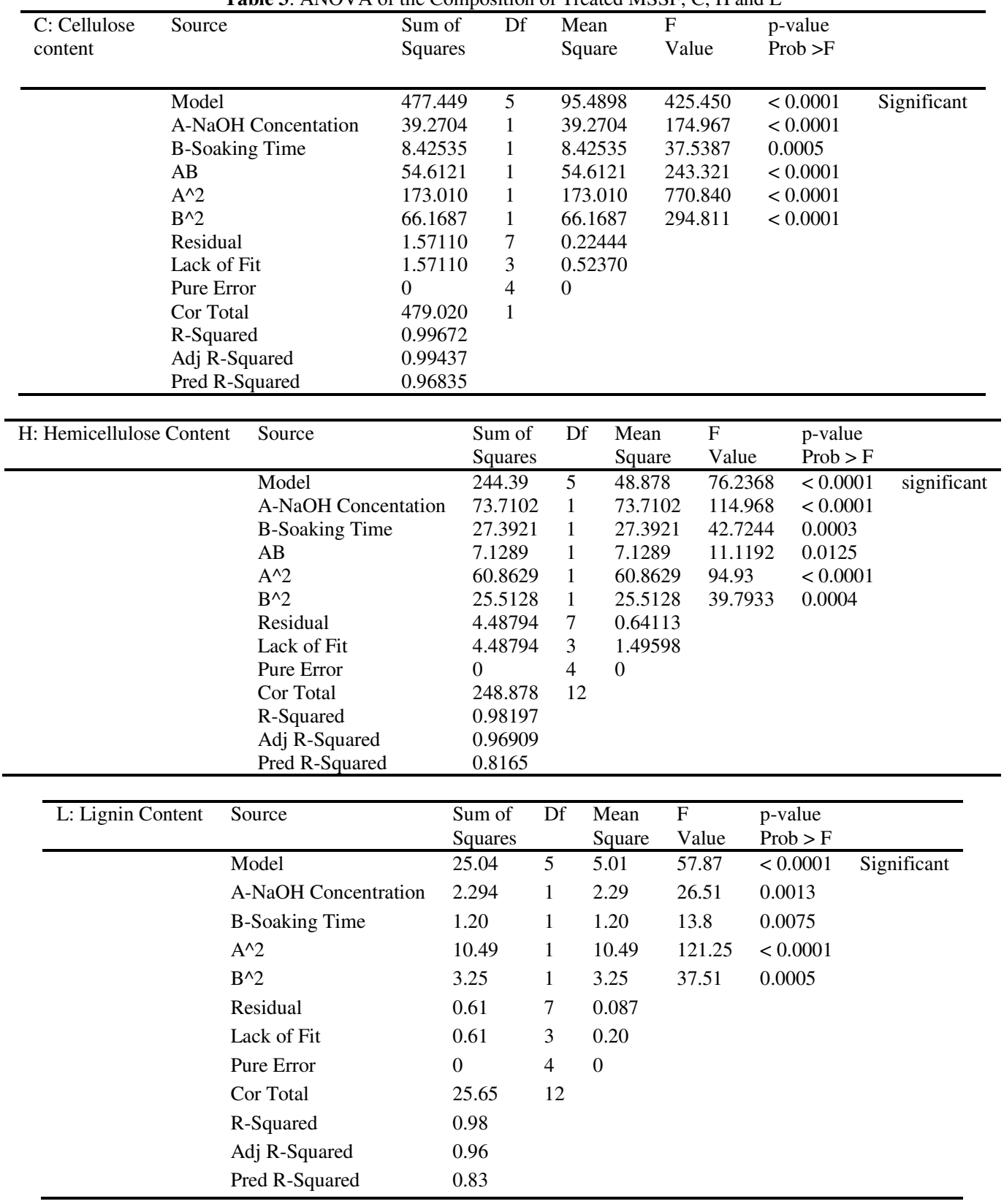

Analysis of Response Surface Plots for Treated MSSF Composition: The RSM plots for treated
MSSF composition was illustrated in Fig 1. It shows that the cellulose content depends on concentration of 
alkali treatment and residence time of soaking. This means that the yield of the cellulose content improves when the concentration of alkali treatment in the solution and the time of immersion increase. This observation was due to more disruptions of agrolignocelluloses component which leads to dissolution of jelly-like materials from the agro-waste to the solution. Similar observations were recorded by previous scholars (Kim and Han, 2012; Shaihaidu and Soh, 2016; Iroba et al., 2013).
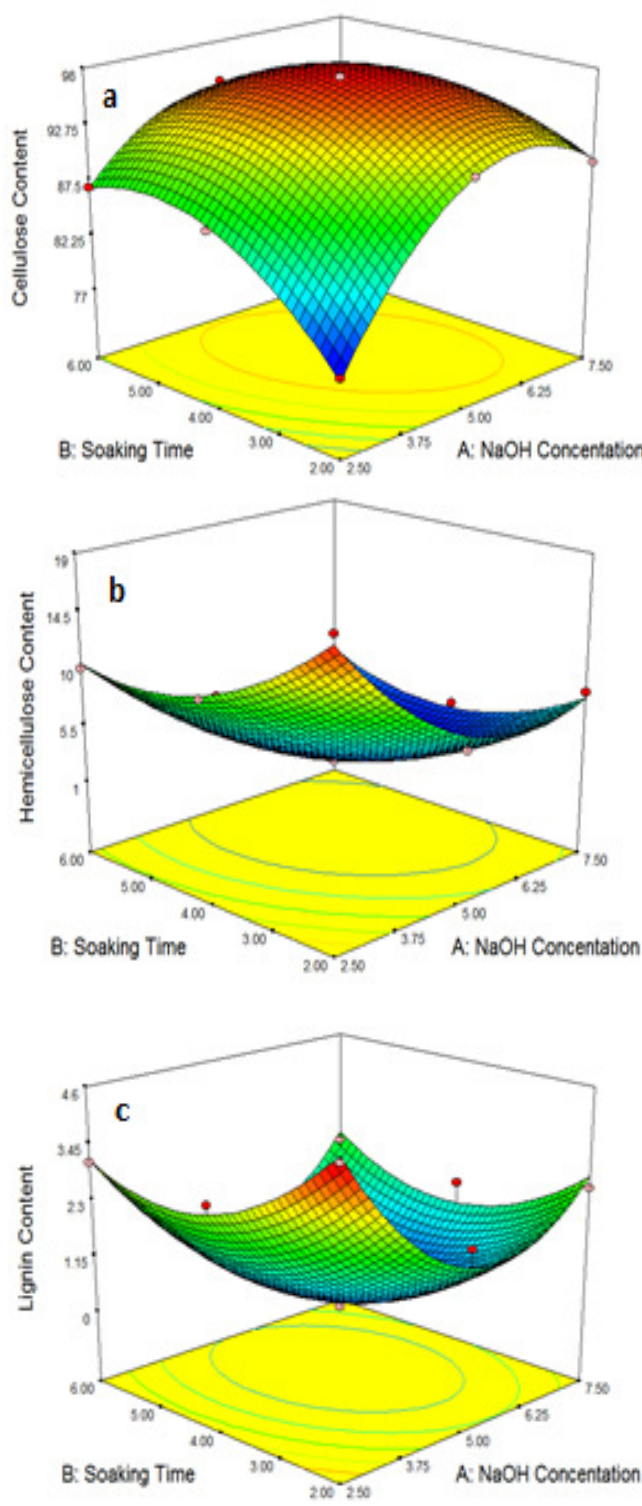

Fig 1: 3-D response surface plots of treated MSSF composition for (a) cellulose (b) hemicellulose (c) lignin content as a function of $\mathrm{NaOH}$ concentration and soaking time.

Fig 1 (b-c) which demonstrated the RSM plots for removal of hemicelluloses and lignin content relates with alkali concentration and solution soaking time. The reduction in hemicellulose and lignin content increases, as the concentration of $\mathrm{NaOH}$ and immersion time increases. This is because the hemicelluloses and lignin content may have been force out from the plant fiber and then dissolves in the solution. These unwanted components are finally rinsed out with distilled water. The optimum conditions for the entire process which is favourable to the responses (cellulose, hemicellulose and lignin content) is at $6.09 \% \mathrm{NaOH}$ concentration and soaking time of $5.22 \mathrm{hrs}$. Similar observation was recorded by previous researchers (Kim and Han, 2012; Shaihaidu and Soh, 2016; Iroba et al., 2013) at their own optimum conditions.

Analysis of Model Adequacy for Treated MSSF Composition: The predicted and actual plots of pretreated MSSF composition were captured in Fig. 2(a-c). The plots for $\mathrm{C}, \mathrm{H}$ and $\mathrm{L}$ as can be seen in Fig 2(a), Fig 2(b) and Fig 2(c), respectively. The predicted versus actual for Fig 2(a-c) confirmed that predicted and actual treated MSSF compositional values of respective plotted points were vehemently close to the diagonal line in the graph. This observed trend is as a result of better correlation of experimental and predicted cellulose, hemicelluloses, and lignin content. This show that models for forecasting the chemical modified MSSF composition using RSM of CCD fitted the experimental results. Several researchers have obtained similar trend of results (Myers et al., 2002; Myers, 2004; Montgomery, 2011, Government et al., 2018).

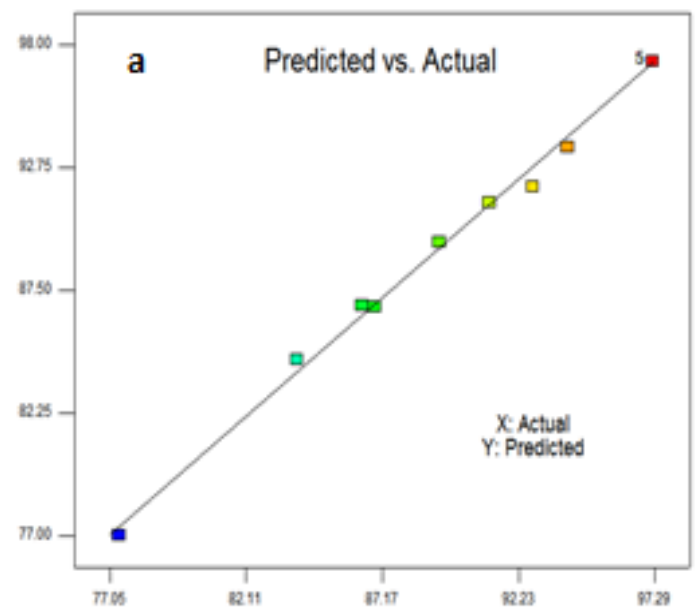



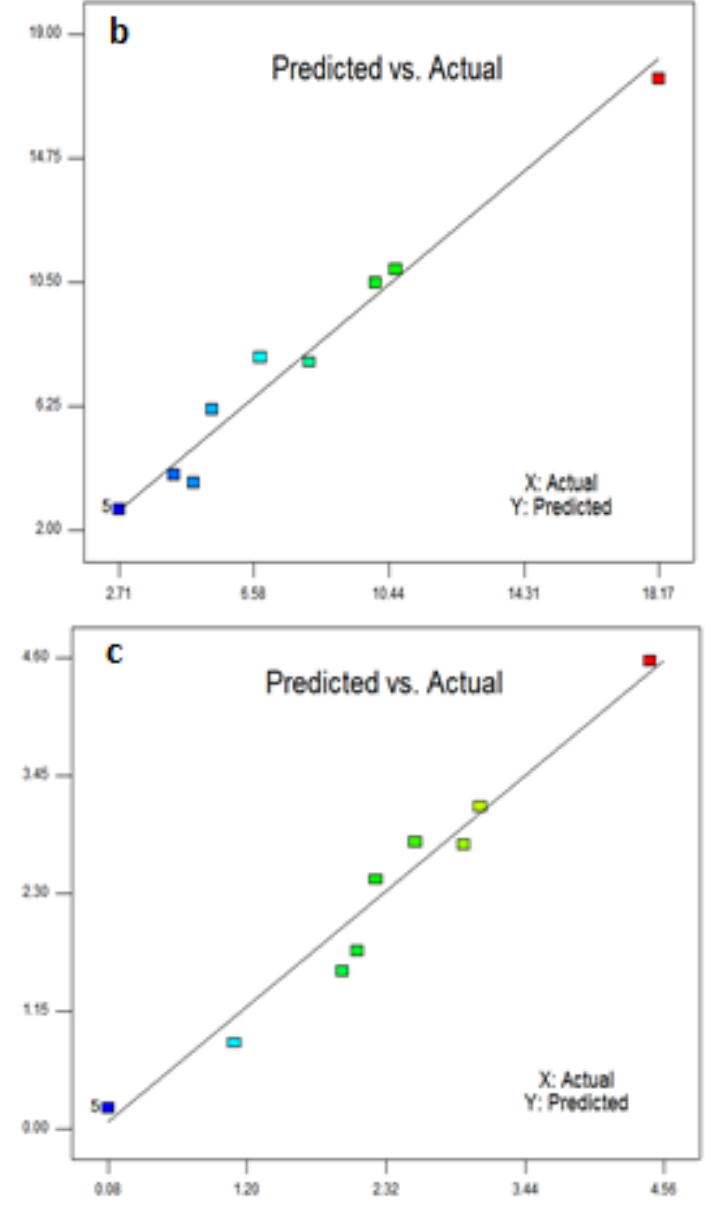

Fig. 2: Predicted versus actual plots of treated MSSF composition for (a) C (b) H (c) L.
Optimization and Model Validation: The optimal parameters for the yield of cellulose content, the removal hemicellulose and lignin content were displayed in the overlay plot in Fig.3. The maximum cellulose content was recorded at $94.8002 \%$, while the hemicelluloses and lignin content were $2.2779 \%$ and $0.508502 \%$, respectively. Also, process conditions occurred at $6.09 \%$ wt $\mathrm{NaOH}$ concentration and soaking time of $5.22 \mathrm{hr}$.

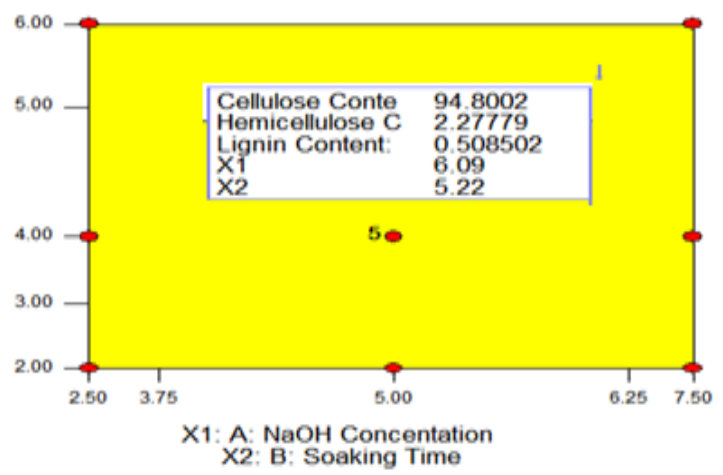

Fig. 3: Overlay plot for optimal condition of treated MSSF composition

The validation of treated MSSF composition at optimum condtion for the predicted using CCD and the experimental result is displayed in Table 4 . The relative percentage deviation modulus when the comparison of experimental treated MSSF composition and predicted results by the application of RSM indicated that it is less than $0.4 \%$. This is an indication of good prediction of the treated MSSF composition using RSM.

Table 4: Model validation of treated MSSF composition at optimal condition

\begin{tabular}{|l|l|l|l|l|l|}
\hline $\begin{array}{l}\text { Treated } \\
\text { MSSF } \\
\text { Composition }\end{array}$ & $\begin{array}{l}\text { NaOH } \\
\text { concentration } \\
(\%)\end{array}$ & $\begin{array}{l}\text { Soaking } \\
\text { Time } \\
(\mathbf{h r})\end{array}$ & $\begin{array}{l}\text { Predicted Treated } \\
\text { MSSF Composition by } \\
\text { RSM (\%) }\end{array}$ & $\begin{array}{l}\text { Experimental } \\
\text { Results of Treated } \\
\text { MSSF Composition } \\
(\%)\end{array}$ & $\begin{array}{l}\text { Relative } \\
\text { Percentage } \\
\text { Deviation Error } \\
(\%)\end{array}$ \\
\hline C & 6.09 & 5.22 & 94.8002 & 94.7594 & 0.043038 \\
\hline H & 6.09 & 5.22 & 2.27779 & 2.2851 & 0.32093 \\
\hline L & 6.09 & 5.22 & 0.508502 & 0.5104 & 0.37325 \\
\hline
\end{tabular}

Conclusion: The effect of varying $\mathrm{NaOH}$ concentration and soaking time on the chemical composition (cellulose, hemicelluloses and lignin content) of Mango Seed Shell Flour was analyzed in this work. The optimum treatment condition of MSSF was also investigated. The treated MSSF showed an improvement in cellulose content and reduction in its hemicelluloses and lignin content. This novel treated filler is recommended for use as a reinforcing material in indoor purpose composite application.

\section{REFERENCES}

AKPAKE, DD (2017). The effect of sodium hydroxide treatment on the compositions of shea butter bark wood flour. Bachelor of Science Thesis. Federal University Wukari, Taraba State, Wukari, Unpublished. 
BEHERA, S; ARORA, R; NANDHAGOPAL, N; KUMAR, S (2014). Importance of chemical pretreatment for bioconversion of lignocellulosic biomass. Renew. Sustain. Ener. Reviews. 36:91106.

BINOD, P; SINDHU, R; SINGHANIA, RR; VIKRAM, S; DEVI, L; NAGALAKSHMI, S; KURIEN, N; SUKUMARAN, RK; PANDEY, A (2010). Bioethanol production from rice straw: an overview. Biores. Technol. 101(13):4767-74.

BOGOEVA-GACEVA, G; AVELLA, M; MALINCONICO, M; BUZAROVSKA, A: GROZDANOV, A; ERICA, ME (2007). Natural fiber eco-composites. Polym. Compos., 28(1), 98-107.

CAMESASCA, L; RAMÍREZ, MB; GUIGOU, M; FERRARI, MD; LAREO, C (2015). Evaluation of dilute acid and alkaline pretreatments, enzymatic hydrolysis and fermentation of napiergrass for fuel ethanol production. Bio. Bioener., 74: 193-201.

CHEN, Y; SHARMA-SHIVAPPA, RR; KESHWANI, D; CHEN, C (2007). Potential of agricultural residues and hay for bioethanol production. Appl. Biochem. Biotechnol. 142: 276-290.

COTANAA, F; BARBANERAA, M; FOSCHINIA, D, LASCAROA E, BURATTI C (2015). Preliminary optimization of alkaline pretreatment for ethanol production from vineyard pruning. ATI 70th Conf. Proc, Ener. Proc, 82: 389 - 394

DUNGANI, R; KARINA, M; SUBYAKO, SA; HERMAWAN, A; HADIYANE, A (2016). Agricultural waste fibers towards sustainability and advance utilization: A review, Asi. J. Pl. Sci., 15: 42-55.

GOVERNMENT, RM; ONUKWULI, OD; ANI, AK 2017. Chemically treated avocado wood flourLLDPE composite, Usa. Uni. J. Mater. Sci., $27-$ 40.

GOVERNMENT, RM; ONUKWULI, OD; JIBATSWEN, TY (2018). Optimization of Chemical Treatment of Avocado Pear Wood Filler on the Properties of LDPE Composites, Int. Conf. Proc.: Fac. Eng., UNIZIK. 499$509.13^{\text {th }}-14^{\text {th }}$ August.
Haristov, V; Vasileva, S (2003). Dynamic mechanical and thermal properties of modified polypropylene composites, wood fibre composites. Macromol. Mater. Eng., 288:798806.

HADI, AE (2011). Characterisation and optimization of mechanical, physical and thermal properties of short abaca (Musa TextileNee) fibre reinforced high impact polystryrene composites. Ph.D. thesis, University Putral Malaysia.

KIM, I; HAN, JI (2012) Optimization of alkaline pretreatment conditions for enhancing glucose yield of rice straw by response surface methodology. Bio. Bioener., 46:210-7.

KUCHI, K (2000). Hopped delay for multiply process power control and handover procedure and optimization, Irving USA, Wiley.

IROBA，KL; TABIL，LG; DUMONCEAUX，T; BAIK, OD (2013). Effect of alkaline pretreatment on chemical composition of lignocellulosic biomass using radio frequency heating. Biosyst. Eng., 116(4):385-98.

MAHYATI. P; PATONG, AR; DJIDE, MN; TABA, DP (2013). Biodegradation of Lignin from Corn Cob by Using a Mixture of Phanerochaete Chrysosporium, Lentinus Edodes and Pleurotus Ostreatus, Int. J. Sci. Technol.Res., 2 (11): 79-82.

Mayers, R; Montgomery, D; Vinning, G; Borror, CM; Kowalski, SM (2004). Response surface methodology: A prospective and a literature survey. J. Qual. Technol.., 36, 53-77.

MCINTOSH, S; VANCOV, T (2011). Optimisation of dilute alkaline pretreatment for enzymatic saccharification of wheat straw. Biom. Bioener. 35: 3094-3103.

MONTGOMERY, DC (2011). Design and Analysis of Experiment.5th ed., John Wiley and Sons, New York.

MYERS, RH; MONTGOMERY, DC (2002). Response Surface Methodology, John Wiley \& Sons, Inc., USA.

MYERS, RH: MONTGOMERY, DC; ANDERSONCOOK, CM (2009). Response surface methodology-process and product optimization using design experiment. $3^{\text {rd }}$ edition, Ney Jersey: John Wiley and Son Inc. 
NACHTIGALL，SMB; CERVERIA，GS; ROSA, SML (2007). New polymeric-coupling agent for polypropylene/wood flour composites. Polym. Test., 26: 619-628.

NETRAL, B; SABU, T; CHAPAL, KD. RAMESHWAR, A (2012). Analysis of morphology and mechanical behaviours of bamboo flour reinforced polypropylene composites. Nep. J. Sci. Technol., 13(1); 95-100.

NUNEZ, AJ; KENNY, JM; REBOREDO, MM; ARANGUREN, MI; MARCOVICH, NE (2002). Thermal and dynamic mechanical characterization of polypropylene-wood flour composites. Polym. Eng. Sci., 42:733-742.

OBASI, HC (2015). Peanut filled poltetheylene composites; effects of filler content and compatibilizer on properties. J. Polym. Sci. http//dx.doi.org/10.1155/2015/189289: 1-9.

OUSHABI, A; SAIR, S; OUDRHIRI, HF; ABBOUD, Y; TANANE P; EL BOUARI, OA (2017). The effect of alkali treatment on mechanical properties of date palm fiber (DPF)polyurethane composite. S. Afr. J. Chem. Eng., 23: 116-123.

PATPENI, P; RUSLY, AR; ROSNITA, AT; KHALINA, A (2015). Response surface methodology for the optimization of preparation of biocomposites based on poly(lactic acid) and duran peel cellulose. Sci. W. J., 1-12.
ROWELL, RM (2005). Chemical modification of wood. In: handbook of wood chemistry and wood composites. (Ed Rowell R.W.), Taylor and Francis CRC Press, USA.

SHUHAIDA, H; SOH, KG (2016). Effect of sodium hydroxide pretreatment on rice straw composition, Ind.J. Sci. Technol., 9(21): 1-9

SOURY, E; BEHRAVESH, AH; ROULANI, EE; ZOLFAGHARI, A (2009). Design, optimization and manufacturing of wood-plastic pallet. Mater. Des., 30: 4183-4191.

SUN, R; LAWTHER, JM; BANKS, WB (1995). Influence of alkaline pretreatments on the cell wall components of wheat straw. Indust. $\mathrm{Cr}$. Prod., 4(2):127-45.

THYGESEN, A; THOMAS, AB; DANIEL, G; LILHOLT, H (2007). Comparisons of composites made from fungal defibrated hemp with composites of traditional hemp yarn. Ind. Cr. Prod. 25:147-159.

WU, J; YU, D; CHAN, C; KIM, J; MAI, Y (2000). Effect of fiber pre-treatment condition on the interfacial strength and mechanical properties of wood fiber/pp composite. J. Appl. Polym. Sci., 76: 1000-1010.

ZHENG, Y; PAN, Z.; ZHANG, R (2009). OVERVIEW OF BIOMASS PRETREATMENT for cellulosic ethanol production. Int. J. Agr. Bio. Eng., 2: 51-68. 